\title{
Case report of ascending colon cancer and multiple jejunal GISTs in a patient with neurofibromatosis type 1 (NF1)
}

Liang Shang ${ }^{1 \dagger}$, Zhen Fang ${ }^{1 \dagger}$, Jin $\mathrm{Liu}^{2 \dagger}$, Fengying $\mathrm{Du}^{1 \dagger}$, Haiyan Jing ${ }^{3}$, Yali X $\mathrm{u}^{3}$, Kangdi Dong ${ }^{1}$, Xiaoman Zhang ${ }^{4}$, Hao $\mathrm{Wu}^{1}$, Changqing Jing ${ }^{1,5^{*}}$ and Leping $\mathrm{Li}^{1,5^{*}}$ (D)

\begin{abstract}
Background: NF1(Neurofibromatosis type 1) is an autosomal dominant genetic disorder. Patients with NF1 have an increased risk of developing benign or malignant tumours, such as gastrointestinal stromal tumours (GISTs). However, the coexistence of NF1, GIST and colon cancer is very rare, and few cases have been reported in the literature.

Case presentation: We admitted a case of a 64-year-old man with type 1 neurofibromatosis, GISTs, and ascending colon cancer. This case was characterized by café-au-lait macules, discrete cutaneous neurofibromas, nodular neurofibromas, multiple jejunal tumours, and ascending colon cancer. Laparoscopic exploration revealed ascending colon cancer and multiple jejunal tumours. Laparoscopic right hemicolectomy and local excision of the jejunal tumours were performed successfully. The pathological results confirmed moderate differentiated adenocarcinoma of the ascending colon with multiple jejunal GISTs (low risk, very low risk). Moreover, the immunohistochemistry results of multiple jejunal GISTs suggest that NF1 is positive. Whole-exome sequencing (WES) of colon cancer revealed mutations in more than 20 genes, including KRAS, PIK3CA, APC, SMAD4, etc. The results of whole-exome sequencing (WES) of jejunal GISTs revealed an NF1 mutation and no KIT or PDGFR gene mutation.

Conclusion: We report a rare case of simultaneous NF1, GIST and colon adenocarcinoma. For patients with NF1, benign and/or malignant tumours are often combined. Therefore, these patients should undergo regular physical examinations so that early detection and early treatment can be achieved.
\end{abstract}

Keywords: NF1, GIST, Colon cancer

\section{Background}

NF1 is an autosomal dominant disease with an incidence of approximately 1 in 2600 to 3000 individuals. Approximately one-half of the cases are inherited [1]. NF1 affects multiple organ systems and has a wide range of variable clinical manifestations [2]. The most characteristic clinical manifestations of NF1 are caféau-lait macules and multiple neurofibromas. Other manifestations include neurological symptoms, skeletal dysplasias and visceral injuries. The pathogenic

\footnotetext{
* Correspondence: jing66510122@sina.com; lileping@medmail.com.cn ‘Liang Shang, Zhen Fang, Jin Liu, Fengying Du own equal first authorship 'Department of Gastroenterological Surgery, Shandong Provincial Hospital Affiliated to Shandong University, Jinan, Shandong, China

Full list of author information is available at the end of the article
}

gene for NF1 is located on the autosome 17q11.2. The gene encoding NF1 was defined in 1991 [3]. In the case of the disease, this chromosomal locus is deleted so that the patient cannot produce the corresponding neurofibromin protein. Neurofibromatosis protein is a tumour suppressor that slows cell proliferation by accelerating the reduction of the proto-oncogene $\mathrm{p} 21$ ras, which plays a major role in the intracellular mitosis signal transduction system. Its function and role in tumourigenesis and other manifestations of NF1 have been studied in depth.

Patients with NF1 have an increased risk of developing GISTs and other benign or malignant tumours [4-6]. In patients with NF1, GIST often occurs in the small

(c) The Author(s). 2019 Open Access This article is distributed under the terms of the Creative Commons Attribution 4.0 International License (http://creativecommons.org/licenses/by/4.0/), which permits unrestricted use, distribution, and reproduction in any medium, provided you give appropriate credit to the original author(s) and the source, provide a link to the Creative Commons license, and indicate if changes were made. The Creative Commons Public Domain Dedication waiver (http://creativecommons.org/publicdomain/zero/1.0/) applies to the data made available in this article, unless otherwise stated. 
intestine (more than 70\%), usually with multiple tumours that have different molecular pathologies $[7,8]$.

Currently, there is no definitive treatment, and clinical management is limited to monitoring and symptomatic treatment for specific complications, usually surgery.

\section{Case presentation}

A 64-year-old man was admitted to our hospital on September 2, 2018 because of abdominal pain with low fever for more than 2 months. The patient had a history of NF1. At the age of 14 years, subcutaneous nodules began to appear in the elbow and gradually began to appear throughout the whole body. The patient had no history of hypertension, coronary heart disease, diabetes, etc. Physical examination revealed café-au-lait macules of varying sizes and multiple subcutaneous nodules and skin fibromas. (Fig. 1) Colonic endoscopy revealed that the mass was located in the ascending colon near the ileocaecum, and the surface of the tumour was erosive. Pathological examination of a colon tumour biopsy revealed moderate differentiated adenocarcinoma. Blood tests showed mild anaemia (HB $101 \mathrm{~g} / \mathrm{L}$ ), and tumour markers and coagulation indicators were normal. Abdominal contrast-enhanced computed tomography $(\mathrm{CT})$ scan showed irregular thickening of the ascending colon walls and inhomogeneous enhancement, consistent with colon cancer CT performance. Multiple enlarged lymph nodes were observed around the tumour. CT also revealed multiple jejunal masses, and the clinical impression may be GISTs (Fig. 2). The clinical diagnoses were ascending colon cancer (cT4aN + M0), NF1, and multiple jejunal tumours (GISTs?). None of his family had a similar performance.

During laparoscopic exploration, a tumour was found in the ascending colon, which manifestly invaded the serous membrane, and multiple enlarged lymph nodes were observed around the tumour. Additionally, multiple small intestine masses were observed in the jejunum within the range of $10-50 \mathrm{~cm}$ from Treitz's ligament. The largest mass was approximately $3 \mathrm{~cm}$, and the smaller masses were approximately $0.5-2 \mathrm{~cm}$ in diameter. (Fig. 3) Subsequently, the ascending colon and jejunal tumours were excised under laparoscopy.

Pathology and whole exon sequencing were performed on the ascending colon and multiple jejunal tumours.

Pathologically, the resected ascending colon tumour was a moderately differentiated adenocarcinoma with one lymph node metastasis (1/18) - pT4a pN1a cM0 stage IIIB according to the TNM staging of AJCC Guidelines Version 3.2018.

The IHC results for colon cancer: wt-p53, CK818+, MLH1+, PMS2+, MSH2+, MSH6+. (Fig. 4) Furthermore, immunohistochemistry results suggest that NF1 is over-

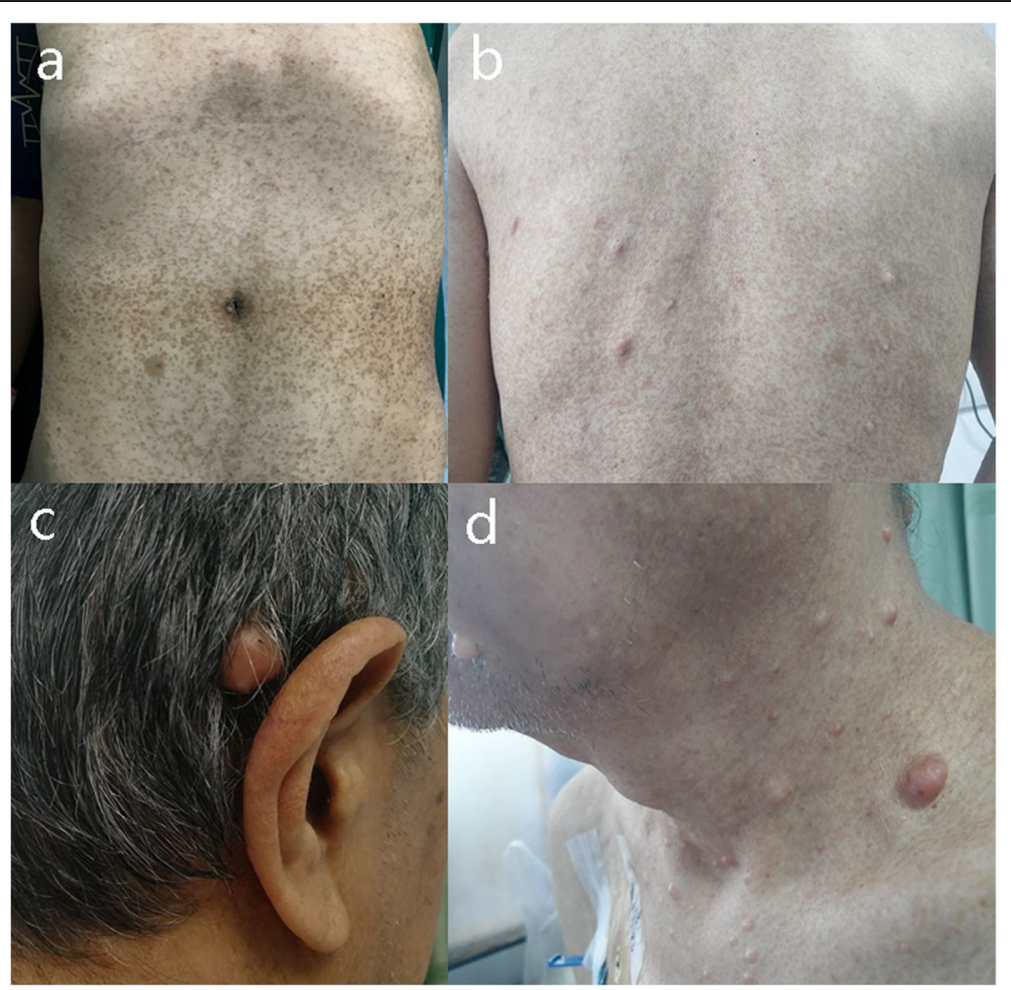

Fig. 1 a, b Café-au-lait macules, c, d Neurofibromas 


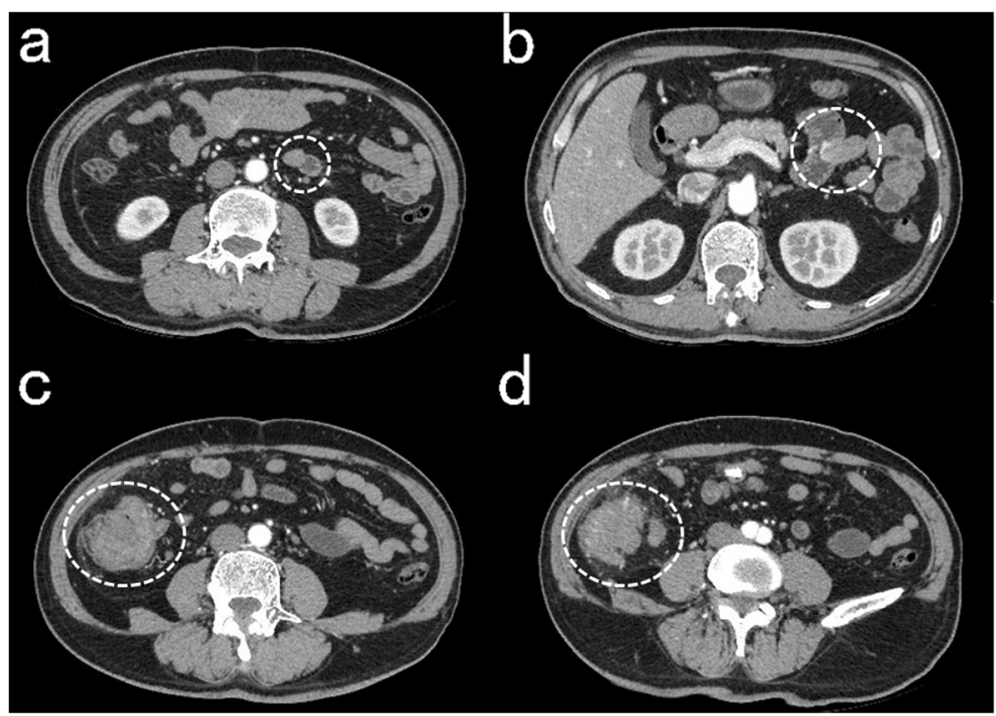

Fig. $2 C T(\mathbf{a}, \mathbf{b})$ Jejunal GISTS, c, d Ascending colon cancer

stained. (Fig. 5a) The pathological result for jejunal tumours indicated low or very low risk GIST $(<5 / 50 \mathrm{HPF}$; $3.7 \mathrm{~cm}, 2.5 \mathrm{~cm}, 0.5 \mathrm{~cm})$, positive for CD117, Dog-1, CD34, SMA, negative for desmin, CK818. (Fig. 6) Immunohistochemistry results indicated that NF1 was positive. (Fig. 5b).

The whole-exome sequencing (WES) results of colon adenocarcinoma revealed mutations in 29 genes, including KRAS, PIK3CA, APC, SMAD4, etc. The WES results for stromal tumours showed an NF1 mutation, and no PDGFRA or KIT mutation. The specific characteristics of colon cancer and GISTs are shown in Table 1.

The patient recovered smoothly and was discharged on the 7th day after surgery. Because the risk level of jejunal GISTs was low and very low, and imatinib was

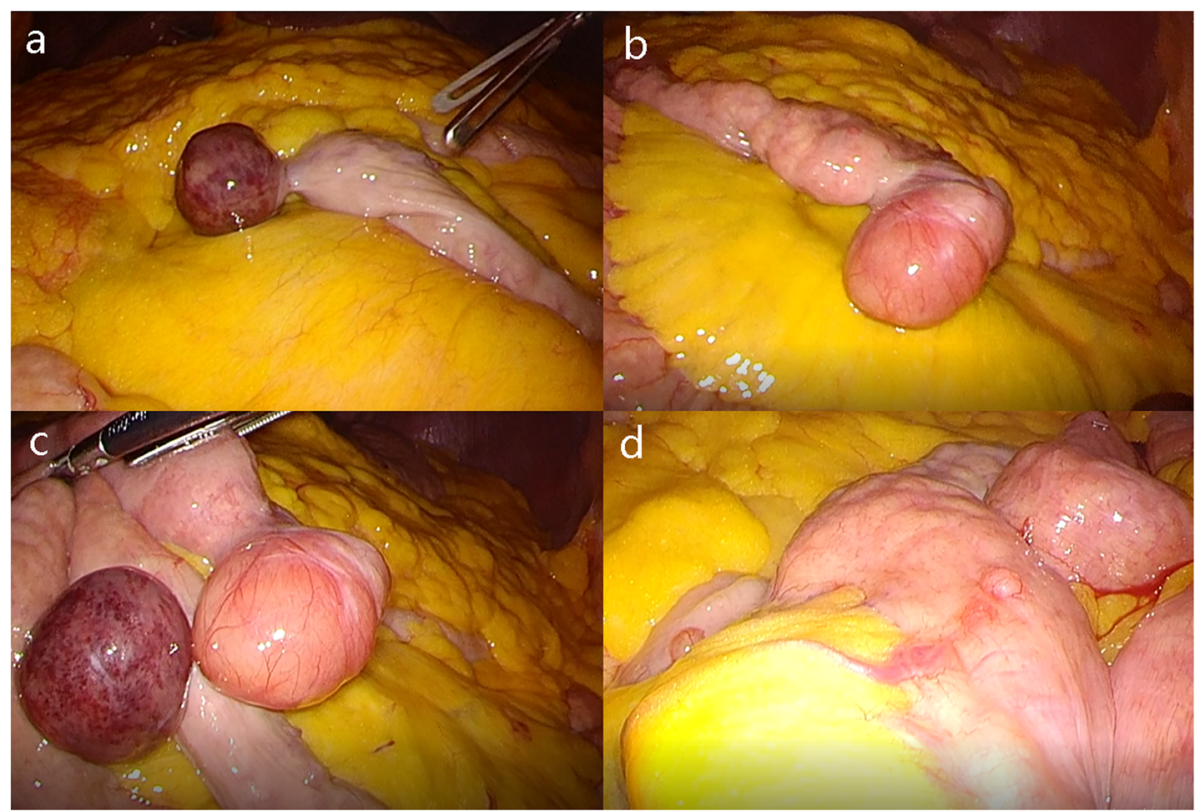

Fig. 3 Laparoscopic exploration showing jejunal tumours (a, b, c, d) 


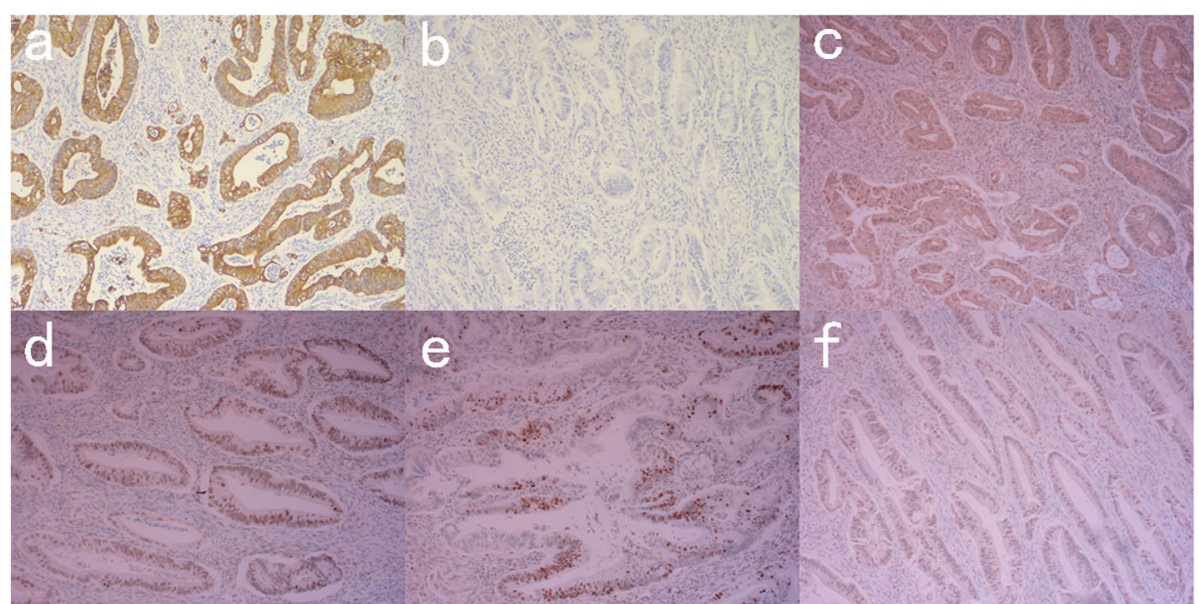

Fig. $4 \mathrm{HC}$ of ascending colon cancer (a) CK818+, b wt-p53, c MLH1+, d MSH2+, e MSH6+, f PMS2+

not administered after surgery. We continued follow up. To date, the patients have undergone 12 cycles of chemotherapy (FOLFOX regimen). No recurrence was observed in the 12-month follow-up period.

\section{Discussion and conclusions}

Neurofibromatosis type 1 (NF1), also known as von Recklinghausen disease, is caused by a mutation in the NF1 gene located on chromosome 17q11.2 [9, 10]. Neurofibromin is a protein product encoded by NF1 that is expressed in many tissues, including the spleen, kidneys, brain, and thymus.

NF1 has a variety of diagnostic features, such as multiple neurofibromas, freckles, café-au-lait macules and iris nodules [11]. If GIST is present in patients with NF1, the GIST usually does not have a KIT mutation
$[12,13]$. Therefore, the response of patients with NF1related GISTs to tyrosine kinase inhibitor imatinib treatment is poor [13]. In this case, the patient had multiple intestinal stromal tumours, and WES revealed NF1 mutations and no KIT or PDGFRA mutations. This finding indicates that the formation of GISTs may be related to an NF1 mutation.

Patients with NF1 are more likely to develop malignant tumours, such as breast cancer, colorectal cancer, stomach cancers, etc. [14] Eui Tae Kim reported 125 cases of NF1 patients in 2012, among which malignancy occurred in 16 patients. The location of the tumour includes the central nervous system, lung, breast, stomach, small intestine, colon, liver, etc. [15] Patients with NF1 are more likely than normal people to develop malignant tumours.

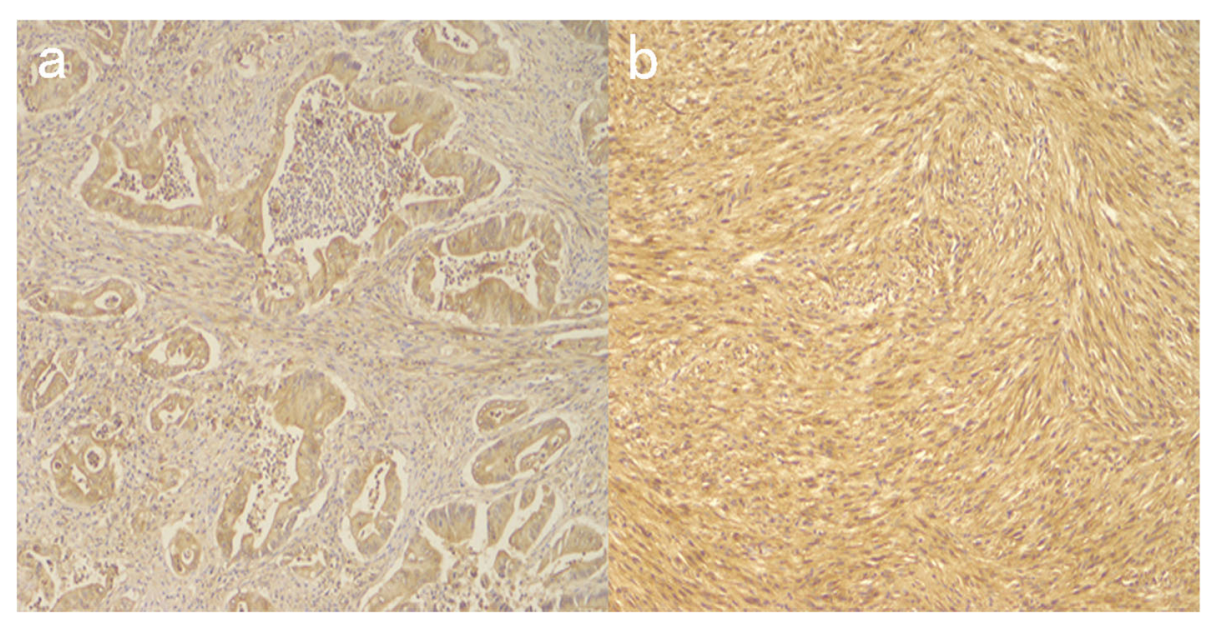

Fig. $5 \mathrm{IHC}$ of NF1 (a) Ascending colon cancer, b Jejunal GISTs 


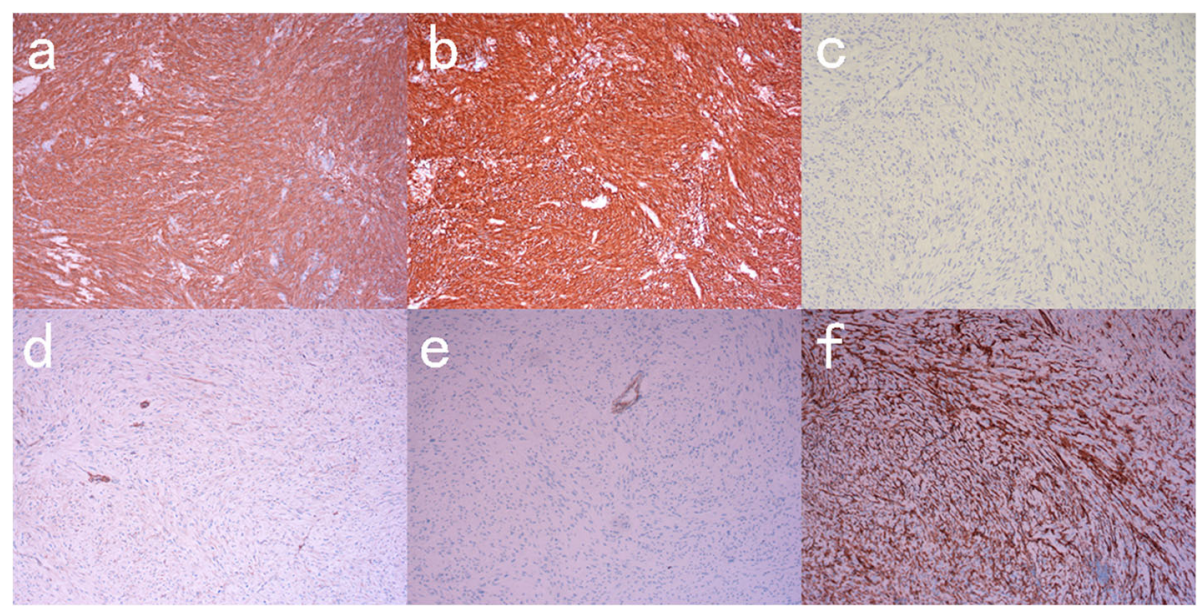

Fig. 6 IHC of jejunal GISTs (a) CD117+, b dog-1+, c CK818-, d SMA+, e desmin-, f CD34+

Studies have reported that neurofibromin can directly inhibit the activation of the RAS signalling pathway. The inactivation of NF1 primarily leads to the uncontrolled activation of RAS [16]. Uncontrolled RAS activation induces the activation of mitogenactivated protein kinase (MAPK) and extracellular signal-regulated kinases 1 and 2 (ERK1 and ERK2). The activation of RAF/MAPK stimulates transcription and cell growth. The activation of the aberrant RAS signalling pathway also leads to cell proliferation and survival through other pathways, such as the PI3KmTOR pathway [17]. Whole-exome sequencing of fresh colon cancer tissue revealed a KRAS mutation. We consider that KRAS is abnormally regulated due to neurofibromin 1 , which is unable to produce normal
RAS protein, leading to intracellular signal transduction disorder, uncontrolled cell proliferation and cancer. Patients with NF1 have a high risk of developing malignant tumours, but there are currently no targeted drugs for the effective treatment of NF1. For patients with NF1, regular physical examination, early discovery, and early treatment are recommended.

In conclusion, we present a rare patient with NF1 associated with multiple GISTs and ascending colon adenocarcinoma. Patients with NF1 often have benign tumours and are more likely to develop malignant tumours than normal people. Therefore, these patients should undergo regular physical examinations so that early discovery and treatment can be achieved.

Table 1 Specific characteristics of colon adenocarcinoma and GISTS

\begin{tabular}{|c|c|c|c|c|}
\hline & Colon adenocarcinoma & GIST (1) & GIST (2) & GIST (others) \\
\hline Location & Ascending colon & $10-50 \mathrm{~cm}$ from the Treitz's ligament & $\begin{array}{l}10-50 \mathrm{~cm} \text { from the } \\
\text { Treitz's ligament }\end{array}$ & $\begin{array}{l}10-50 \mathrm{~cm} \\
\text { from the } \\
\text { Treitz's } \\
\text { ligament }\end{array}$ \\
\hline $\begin{array}{l}\text { Size } \\
(\mathrm{cm})\end{array}$ & $5 \times 3 \times 3$ & $3.7 \times 2.2 \times 2.8$ & $2.5 \times 2.5 \times 2.3$ & $0.5 \times 0.5 \times 0.6$ \\
\hline Grade & moderately differentiated & low risk & low risk & very low risk \\
\hline \multirow[t]{2}{*}{$\mathrm{IHC}$} & NF1 pan-stained, wt-p53, CK818+ & \multirow{2}{*}{$\begin{array}{l}\text { NF1+, CD117+, Dog-1+, CD34+, S-100-, } \\
\text { E-cad-, CK818-, SMA+, Caldesmon+, } \beta- \\
\text { catenin+, E-cad-, Ki-67+ (4\%) }\end{array}$} & \multirow{2}{*}{$\begin{array}{l}\text { NF1+, CD117+, Dog-1+, } \\
\text { CD34+, S-100-, E-cad-, } \\
\text { CK818-, SMA+, desmin- }\end{array}$} & \multirow{2}{*}{$\begin{array}{l}\text { CD117+, Dog- } \\
1+, \text { S-100-, } \\
\text { SMA+, } \\
\text { desmin- }\end{array}$} \\
\hline & $\mathrm{MLH} 1+, \mathrm{PMS} 2+, \mathrm{MSH} 2+, \mathrm{MSH} 6+$ & & & \\
\hline \multirow[t]{2}{*}{ WES } & KRAS, PIK3CA, APC, SMAD4 & \multirow[t]{2}{*}{ NF1, MSS, TMB (low) } & \multirow[t]{2}{*}{ NF1, MSS, TMB (low) } & \multirow[t]{2}{*}{-} \\
\hline & $\begin{array}{l}\text { APOB, ATPAF2, CACNA1H, COL6A3, DECR2, DLG2, DOK3, } \\
\text { DYNC111, HCN1, KIAA1841, KIF6, KLRG1, MYOD1, NEFH, } \\
\text { OR10C1, OR8A1, PTPN7, RGS18, RHOBTB1, SPATS2L, } \\
\text { STAC, SYNPO2L, TAS1R2, USH2A, VEPH1 }\end{array}$ & & & \\
\hline
\end{tabular}




\section{Abbreviations}

CA125: Carbohydrate antigen 125; CA19-9: Carbohydrate antigen 199; CA724: Carbohydrate antigen 199; CEA: Carcinoembryonic antigen; CT: Computed tomography; FOLFOX: Oxaliplatin + calcium folinate + fluorouracil; GIST: Gastrointestinal stromal tumour; IHC: Immunohistochemistry; NF1: Neurofibromatosis type 1; NGS: Next-generation sequencing; WES: Whole-exome sequencing; wt-p53: Wild-type p53

\section{Acknowledgements}

The authors would like to thank the Department of Pathology of Shandong Provincial Hospital Affiliated to Shandong University for providing the pathology images used in this case report.

\section{Authors' contributions}

$\mathrm{LL}$ and $\mathrm{CJ}$ made substantial contributions to design the research work. LS, $Z F$, JL and FD made substantial contributions to collecting the clinical samples, and analysing and interpreting the patient data. KD carried out the NGS testing and bioinformatics analysis. $H J$ and $Y X$ performed the histological examination of the tumour tissues. ZF and XZ wrote the initial draft of the manuscript. HW revised the paper for important intellectual content. All authors have read and approved the final manuscript.

\section{Funding}

This work was supported by the National Natural Science Foundation of China (No. 81572355). This fund provided support for personnel and lab supplies.

\section{Availability of data and materials}

Data related to this case report can be acquired from the corresponding author.

\section{Ethics approval and consent to participate}

As this study is a case report, ethics approval was not necessary after consulting the Ethics Committee of Shandong Provincial Hospital Affiliated to Shandong University.

\section{Consent for publication}

Written informed consent was obtained from the patient for publication of the case report and the accompanying images.

\section{Competing interests}

The authors declare that they have no competing interests.

\section{Author details}

'Department of Gastroenterological Surgery, Shandong Provincial Hospital Affiliated to Shandong University, Jinan, Shandong, China. ${ }^{2}$ Department of Gastroenterology, Shandong Provincial Hospital Affiliated to Shandong University, Jinan, Shandong, China. ${ }^{3}$ Department of Pathology, Shandong Provincial Hospital Affiliated to Shandong University, Jinan, Shandong, China. ${ }^{4}$ Department of ENT, Shandong Provincial ENT Hospital, Shandong Provincial ENT Hospital Affiliated to Shandong University, Jinan, Shandong, China. ${ }^{5}$ Department of Gastrointestinal Surgery, Shandong Provincial Hospital Affiliated to Shandong University, Jingwuweiqi Street, 324, Jinan 250021, Shandong, China.

Received: 5 July 2019 Accepted: 18 November 2019

Published online: 05 December 2019

\section{References}

1. Rasmussen SA, Friedman JM. NF1 gene and neurofibromatosis 1. Am J Epidemiol. 2000;151(1):33-40.

2. Gutmann DH, Ferner RE, Listernick RH, Korf BR, Wolters PL, Johnson KJ. Neurofibromatosis type 1. Nat Rev Dis Primers. 2017;3:17004.

3. Gutmann DH, Wood DL, Collins FS. Identification of the neurofibromatosis type 1 gene product. Proc Natl Acad Sci U S A. 1991;88(21):9658-62.

4. Xie R, Fu Kl, Chen SM, Tuo BG, Wu HC. Neurofibromatosis type 1-associated multiple rectal neuroendocrine tumors: a case report and review of the literature. World J Gastroenterol. 2018;24(33):3806-12.

5. Lee JM, Lee JM, Hyun JJ, Choi HS, Kim ES, Keum B, Jeen YT, Chun HJ, Lee HS, Kim CD, et al. Intraductal papillary bile duct adenocarcinoma and gastrointestinal stromal tumor in a case of neurofibromatosis type 1. World J Gastroenterol. 2018;24(4):537-42.

6. Belinsky MG, Rink L, Cai KQ, Capuzzi SJ, Hoang Y, Chien J, Godwin AK, von Mehren M. Somatic loss of function mutations in neurofibromin 1 and MYC associated factor $X$ genes identified by exome-wide sequencing in a wildtype GIST case. BMC Cancer. 2015;15:887.

7. Andersson J, Sihto H, Meis-Kindblom JM, Joensuu H, Nupponen N, Kindblom LG. NF1-associated gastrointestinal stromal tumors have unique clinical, phenotypic, and genotypic characteristics. Am J Surg Pathol. 2005; 29(9):1170-6.

8. Kinoshita K, Hirota S, Isozaki K, Ohashi A, Nishida T, Kitamura Y, Shinomura Y, Matsuzawa Y. Absence of c-kit gene mutations in gastrointestinal stromal tumours from neurofibromatosis type 1 patients. J Pathol. 2004;202(1):80-5.

9. Ledbetter DH, Rich DC, O'Connell P, Leppert M, Carey JC. Precise localization of NF1 to 17q11.2 by balanced translocation. Am J Hum Genet. 1989;44(1):20-4.

10. Ferner RE. Neurofibromatosis 1 and neurofibromatosis 2: a twenty first century perspective. Lancet Neurol. 2007;6(4):340-51.

11. Jett K, Friedman JM. Clinical and genetic aspects of neurofibromatosis 1 . Genet med. 2010;12(1):1-11.

12. Miettinen M, Fetsch JF, Sobin LH, Lasota J. Gastrointestinal stromal tumors in patients with neurofibromatosis 1: a clinicopathologic and molecular genetic study of 45 cases. Am J Surg Pathol. 2006;30(1):90-6.

13. Mussi C, Schildhaus HU, Gronchi A, Wardelmann E, Hohenberger P. Therapeutic consequences from molecular biology for gastrointestinal stromal tumor patients affected by neurofibromatosis type 1. Clin Cancer Res. 2008;14(14):4550-5.

14. Zoller ME, Rembeck B, Oden A, Samuelsson M, Angervall L. Malignant and benign tumors in patients with neurofibromatosis type 1 in a defined Swedish population. Cancer. 1997;79(11):2125-31.

15. Kim ET, Namgung H, Shin HD, Lee SI, Kwon JE, Chang MC, Park DG. Oncologic manifestations of neurofibromatosis type 1 in Korea. J Surg Soc. 2012:82(4):205-10.

16. Redig AJ, Capelletti M, Dahlberg SE, Sholl LM, Mach S, Fontes C, Shi Y, Chalasani P, Janne PA. Clinical and molecular characteristics of NF1-mutant lung Cancer. Clin Cancer Res. 2016;22(13):3148-56.

17. Nix JS, Blakeley J, Rodriguez FJ. An update on the central nervous system manifestations of neurofibromatosis type 1. Acta Neuropathol. 2019. [Epub ahead of print].

\section{Publisher's Note}

Springer Nature remains neutral with regard to jurisdictional claims in published maps and institutional affiliations.

\footnotetext{
Ready to submit your research? Choose BMC and benefit from:

- fast, convenient online submission

- thorough peer review by experienced researchers in your field

- rapid publication on acceptance

- support for research data, including large and complex data types

- gold Open Access which fosters wider collaboration and increased citations

- maximum visibility for your research: over $100 \mathrm{M}$ website views per year

At BMC, research is always in progress.

Learn more biomedcentral.com/submission
} 